\title{
Therapies for Pain in Parkinson Disease: Concerns Related to a Meta-Analysis on Treating Different Types of Pain as if They Were the Same
}

\author{
Karen Gail Raphael \\ New York University College of Dentistry, New York, NY, USA
}

\section{Dear Editor,}

As an academic clinical research scientist studying pain conditions for several decades and as a person who has lived with Parkinson Disease (PD) for more than 8 years, I was initially delighted to see the review and meta-analysis by Qureshi et al. [1] concerning treatment of pain in PD. Good quality meta-analytic reviews can help to reconcile inconsistent findings and small-sample studies within a field. Evaluating best treatments for pain in PD is particularly important, as pain is the most troublesome nonmotor symptom in earlystage PD [2]. It may often precede the onset of motor symptoms [3].

Unfortunately, I fear that this metaanalysis does little to advance treatment of pain in PD. Why? Inherently, to justify combining across different studies, an assumption must have been made that "Parkinson's Pain" (or pain when it occurs in $\mathrm{PD}$ ) is a uniform entity.

This major assumption is unlikely to be correct. Pain is not necessarily of the same type in one person with PD as it might be for another person with PD, and those with PD can experience multiple pains with discrete sensory and anatomic-distribution characteristics. In one survey [4] among 176 home-dwelling PD patients, $53 \%$ of the patients reported one, $24 \%$ reported 2 , and $5 \%$ reported 3 pain types. If the pathophysiological mechanisms underlying different types of pain experienced in PD are variable, a meta-analytic study that combines different types of pain in people with PD and then examines treatment efficacy may reveal nothing with clinical utility that can be appropriately generalized to different types of pain in PD.

The quality and characteristics of pain are different enough that a single individual can describe multiple pain conditions. For example, in early stage $\mathrm{PD}$, even prior to motor symptom manifestation, a person with PD can experience presumed primary "central pain," which cannot be localized to a specific anatomic region [5-7] but is likely due to some lesion of the central somatosensory system. Mechanistically, it appears to describe a type of "nociplastic pain" [8] involving changes in cerebral activation, connectivity, or structures. It is typically successfully treated in drug-naïve PD patients by initiating levodopa therapy but may later be associated with wearing-off periods after dopaminergic therapy has been initiated.

As reviewed recently by Tseng and Lin [7], peripheral nociceptive afferent fibers degenerate early in PD. Peripheral cutaneous denervation can cause peripheral neuropathic pain. Pregabalin or gabapentin have been shown in multiple clinical trials to improve peripheral neuropathic pain [9, 10] but not specifically in samples of individuals with $\mathrm{PD}$. A focused trial of this nature would have major utility; for now, PD patients and their treating clinicians must infer that interventions that have shown robust therapeutic efficacy in clinical trials conducted in different patient samples but with descriptively similar pain symptoms are applicable.

In contrast to pain related to neuropathology, a number of types of nociceptive pain may occur in PD. Musculoskeletal pain may be associated with increased muscle rigidity. It may also be related to dystonia in PD. One study [11] found that nearly $100 \%$ of PD patients with dystonic pain experienced improvement following deep brain stimulation of the subthalamic nucleus versus $61 \%$ of those with musculoskeletal pain and only $14 \%$ of those with low back pain. Since PD is a disorder more common in aged people, musculoskeletal pain may be associated with PD due to age-related comorbidities such as osteoarthritis or other age-related painful conditions [12].
KARGER

(c) 2018 S. Karger AG, Basel

E-Mail karger@karger.com

www.karger.com/ned
Karen Gail Raphael

Department of Oral and Maxillofacial Pathology, Radiology, and Medicine, New York University College of Dentistry

380 Second Avenue, Suite 301, New York, NY 10010 (USA)

E-Mail kgr234@nyu.edu 
The fact that all of these distinct types of pain can be measured on a visual analogue severity scale or other severity scale does not justify collapsing across different types of pain when conducting a meta-analysis. Surveys suggest that the most prevalent type of pain in people with PD is musculoskeletal $[4,13,14]$. Relative high representation of musculoskeletal pain may obscure the efficacy of treatments for less common types of pain in patients with PD.

This is not the first time that clinical trials on pain in PD have been critiqued for failing to separate subtypes of pain. In Lancet Neurology [15], a 2015 commentary noted that a just-published 16-week randomized controlled clinical trial of oral

\section{References}

1 Qureshi AR, Rana AQ, Malik SH, Rizvi SFH, Akhter S, Vannabouathong C, Sarfraz Z, Rana R: Comprehensive examination of therapies for pain in Parkinson's Disease: a systematic review and metaanalysis. Neuroepidemiology 2018;51:190206.

2 Politis M, Wu K, Molloy S, G Bain P, Chaudhuri KR, Piccini P: Parkinson's disease symptoms: the patient's perspective. Mov Disord 2010;25:1646-1651.

3 Farnikova K, Krobot A, Kanovsky P: Musculoskeletal problems as an initial manifestation of parkinson's disease: a retrospective study. J Neurol Sci 2012;319:102-104.

4 Beiske AG, Loge JH, Ronningen A, Svensson E: Pain in parkinson's disease: prevalence and characteristics. Pain 2009;141:173-177.

5 Ford B: Pain in parkinson's disease. Mov Disord 2010;25(suppl 1):S98-S103.

6 Rana AQ, Kabir A, Jesudasan M, Siddiqui I, Khondker S: Pain in parkinson's disease: analysis and literature review. Clin Neurol Neurosurg 2013;115:2313-2317. prolonged-release oxycodone-naloxone [16] did not find that this powerful drug differed from placebo on its primary endpoint of average $24-\mathrm{h}$ pain score, but post hoc analysis did reveal improved pain severity for certain subgroups. The commentary authors note the importance of proper, standardized and well-characterized subgroups of pain in patients with $\mathrm{PD}$, when conducting or summarizing randomized controlled clinical trials on this topic. Without this characterization, important therapeutic effects for specific types of pain might well be obscured, and the "average" most effective pain treatment is only relevant for a non-existent "average" PD pain. Those earlier concerns are echoed here.

7 Tseng MT, Lin CH: Pain in early-stage parkinson's disease: implications from clinical features to pathophysiology mechanisms. J Formos Med Assoc 2017;116:571-581.

8 Kosek E, Cohen M, Baron R, Gebhart GF, Mico JA, Rice AS, Rief W, Sluka AK: Do we need a third mechanistic descriptor for chronic pain states? Pain 2016;157:13821386.

9 Markman JD, Jensen TS, Semel D, Li C, Parsons B, Behar R, Sadosky AB: Effects of pregabalin in patients with neuropathic pain previously treated with gabapentin: a pooled analysis of parallel-group, randomized, placebo-controlled clinical trials. Pain Pract 2017;17:718728.

10 Parsons B, Argoff CE, Clair A, Emir B: Improvement in pain severity category in clinical trials of pregabalin. J Pain Res 2016;9:779-785.

11 Jung YJ, Kim HJ, Jeon BS, Park H, Lee WW, Paek SH: An 8-year follow-up on the effect of subthalamic nucleus deep brain stimulation on pain in parkinson disease. JAMA Neurol 2015;72:504-510.

\section{Acknowledgment}

The author has no non-author contributions requiring acknowledgment.

\section{Disclosure Statement}

The author has no conflicts of interest to declare.

\section{Funding Sources}

The author has no external funding sources relevant to this manuscript to acknowledge.
12 Negre-Pages L, Regragui W, Bouhassira D, Grandjean H, Rascol O; DoPaMiP Study Group: Chronic pain in parkinson's disease: the cross-sectional french dopamip survey. Mov Disord 2008;23:1361-1369.

13 Hanagasi HA, Akat S, Gurvit H, Yazici J, Emre M: Pain is common in parkinson's disease. Clin Neurol Neurosurg 2011;113:11-13.

14 Lin XJ, Yu N, Lin XG, Zhang YF, Chen Y, Zhang K, Wang XS, Liu WG: A clinical survey of pain in parkinson's disease in eastern China. Int Psychogeriatr 2016;28:283-289.

15 Antonini A, Tinazzi M: Targeting pain in parkinson's disease. Lancet Neurol 2015;14: 1144-1145.

16 Trenkwalder C, Chaudhuri KR, MartinezMartin P, Rascol O, Ehret R, Valis M, Satori M, Krygowska-Wajs A, Marti MJ, Reimer K, Oksche A, Lomax M, DeCesare J, Hopp M; PANDA study group: Prolonged-release oxycodone-naloxone for treatment of severe pain in patients with parkinson's disease (panda): a double-blind, randomised, placebo-controlled trial. Lancet Neurol 2015;14:1161-1170. 